\title{
DIRECT ARTERIAL PRESSURE, HEART RATE AND ELECTROCARDIOGRAM DURING HUMAN COITUS
}

\author{
W. A. LITTLER, A. J. HONOUR AND P. SLEIGHT \\ Cardiac Department and Department of the Regius Professor of Medicine, \\ Radcliffe Infirmary, Oxford $O X 26 H E$
}

(Received 27th September 1973)

\begin{abstract}
Summary. Direct arterial blood pressure, heart rate and electrocardiograms were recorded continuously over a 24-hr period in seventy-two human subjects. Seven normotensive subjects (six males and one female) had coitus at home during the period of study. The duration of intercourse ranged from 8 to 20 min and orgasm was achieved by all six males but not by the female. Significant changes in arterial systolic and diastolic pressure and heart rate were noted. Compared with values at the onset of coitus, systolic pressure rose by 20 to $107 \%(+25$ to $120 \mathrm{mmHg}$ ), diastolic pressure by 31 to $60 \%(+25$ to 48$)$ and heart rate increased from 25 to $120 \%$ ( +20 to 87 beats $/ \mathrm{min}$ ). Changes in arterial pressure closely followed changes in heart rate throughout the activity.

Peak arterial pressure and heart rate occurred at the time of orgasm; after which, arterial pressure and, to a lesser extent, heart rate quickly fell to below the precoital level within 20 to $120 \mathrm{sec}$.
\end{abstract}

\section{INTRODUCTION}

Sexual intercourse is a private and spontaneous activity, which is inappropriate for study under laboratory conditions. Masters \& Johnson (1966) made an exhaustive study of the anatomy and physiology of the human sexual response, using adult men and women who were willing to serve as subjects in the laboratory. In reporting their findings, they described marked increases in heart rate and arterial blood pressure during sexual intercourse. Unfortunately, they failed to state the number of observations or the method used to determine the blood pressure.

In this communication, we will describe circulatory changes which were recorded continuously throughout sexual intercourse.

\section{SUBJEGTS AND METHODS}

Direct arterial blood pressure, heart rate and the electrocardiogram (ECG) have previously been recorded continuously over a 24 -hr period in seventy-two human subjects (Littler, Honour, Sleight \& Stott, 1972, 1973; Littler, Honour \& Sleight, 1973).

Seven of these subjects who were normotensive (six males and one femaleTable 1), and who had sexual intercourse in their home environment during 
Table 1. Sex, age, occupation and clinical details of the seven subjects

\begin{tabular}{c|c|c|l|l|l|l|l}
\hline Sttbject & Sex & $\begin{array}{c}\text { Age } \\
\text { (years) }\end{array}$ & Occupation & Partner & $\begin{array}{c}\text { Resting } \\
\text { blood pressure }\end{array}$ & $\begin{array}{c}\text { Chest } \\
\text { X-ray }\end{array}$ & $\begin{array}{c}\text { Electro- } \\
\text { cardiogram }\end{array}$ \\
\hline 1 & $\mathbf{M}$ & 31 & Doctor & Wife & $110 / 60$ & - & - \\
2 & $\mathbf{M}$ & 32 & Lorry driver & Wife & $130 / 70$ & Normal & Normal \\
$\mathbf{3}$ & $\mathbf{M}$ & 20 & Student & Girl friend & $138 / 82$ & - & Normal \\
$\mathbf{4}$ & $\mathbf{M}$ & 22 & Car worker & Wife & $130 / 90$ & Normal & Normal \\
$\mathbf{5}$ & $\mathbf{M}$ & 35 & Doctor & Wife & $136 / 84$ & - & Normal \\
6 & $\mathbf{M}$ & 26 & Builder & Wife & $125 / 80$ & Normal & Normal \\
7 & $\mathbf{F}$ & 31 & School teacher & Husband & $130 / 85$ & - & Normal \\
\hline
\end{tabular}

the 24-hr period of the study, form the basis of this report. All subjects gave fully informed consent to the study. The methods used have been previously described (Littler et al., 1972). Subject 1 was studied with an earlier type of direct arterial pressure recorder using an otherwise similar technique except that the ECG and heart rate were not recorded. The arterial pressure data were included in another publication (Bevan, Honour \& Stott, 1969). Briefly, a Teflon catheter (length, $10 \mathrm{~cm}$; i.d. $0.9 \mathrm{~mm}$ ) was inserted into the left brachial artery using the Seldinger technique. The catheter was connected to a transducer and perfusion pump by a $1-\mathrm{m}$ length of Teflon tubing (i.d. $0 \cdot 35 \mathrm{~mm}$ ), and was perfused with normal saline at about $1.5 \mathrm{ml} / \mathrm{hr}$. The recording system was a miniature (four-channel analogue) tape recorder using standard compact cassettes. The transducer, perfusion pump, and tape recorder were carried in a padded harness at heart level; the reference point for pressure was therefore constant irrespective of the position of the arm. The frequency response of the whole system was flat to $10 \mathrm{~Hz}$. The zero baseline varied less than $2 \mathrm{mmHg}$ over the 24-hr period. The ECG system consisted of bipolar electrodes placed over the V5R-V5L positions. Leads were held in place by electrode discs and secured by surgical tape to minimize movement artifact. The tape cassettes were replayed on a separate playback deck at twenty-five times the recording speed. The output from this playback deck was fed into a u.v. recorder so that compressed or expanded records, for beat-to-beat analysis, might be obtained. The subjects were all studied over a 24-hr period from 09.00 to 09.00 hours. During this time, they attended the laboratory only once for 15 min after a 12-hr period in order to apply a calibration to the tape and to service the perfusion chamber.

When analysing our results, the arterial systolic and diastolic pressures and the heart rate were averaged over ten consecutive beats at 1-min intervals throughout the sexual activity. The records were scrutinized for changes in cardiac rhythm and ST segment shift using previously described criteria (Littler et al., 1972).

\section{RESULTS}

All six males achieved orgasm but the female did not. Table 2 shows the absolute figures for arterial blood pressure and heart rate at 1-min intervals throughout intercourse and these are summarized in Table 3 and in Text-fig. 1. Text-figure 2 


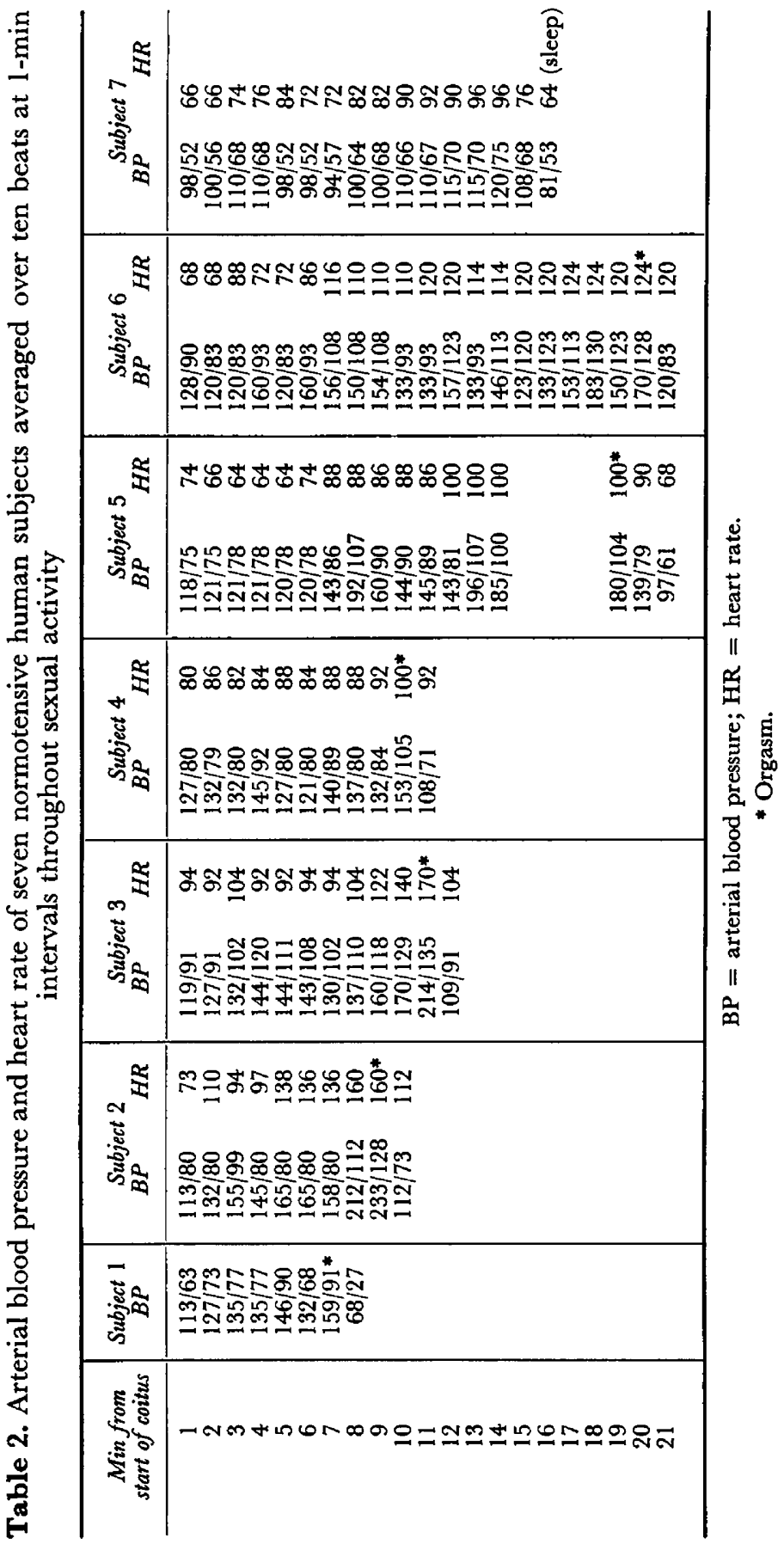


Table 3. A summary of the significant changes in the circulation of seven human subjects during sexual intercourse

\begin{tabular}{c|c|c|c|c|c|c}
\hline Subject & $\begin{array}{c}\text { Duration of } \\
\text { intercourse } \\
(\text { min) }\end{array}$ & Orgasm & $\begin{array}{c}\% \\
\text { Change in } \\
\text { systolic BP }\end{array}$ & $\begin{array}{c}\% \\
\text { Change in } \\
\text { diastolic BP }\end{array}$ & $\begin{array}{c}\% \\
\text { Change in } \\
\text { heart rate }\end{array}$ & $\begin{array}{c}\text { Time for BP to } \\
\text { fall below precoital } \\
\text { value (sec) }\end{array}$ \\
\hline 1 & 8 & + & 59 & 32 & - & 25 \\
2 & 8 & + & 107 & 60 & 120 & 34 \\
3 & 12 & + & 80 & 48 & 81 & 20 \\
4 & 10 & + & 20 & 31 & 25 & 30 \\
5 & 20 & + & 53 & 39 & 52 & 120 \\
6 & 20 & + & 33 & 42 & 76 & 24 \\
7 & 16 & 0 & 23 & 44 & 46 & 20 \\
\hline
\end{tabular}

The pressure and rate changes are the maximum levels achieved. $\mathrm{BP}=$ arterial blood pressure.

shows the typical evolution of these changes in arterial pressure and heart rate. Text-figure 3 shows that there was a linear relationship between the maximum percentage increase in mean arterial pressure during coitus and the maximum percentage increase in heart rate, as compared with levels before coitus. Analysis of the data provided by one subject showed that the arterial pressure began to fall immediately after ejaculation (Text-figs 4 and 5). In the female

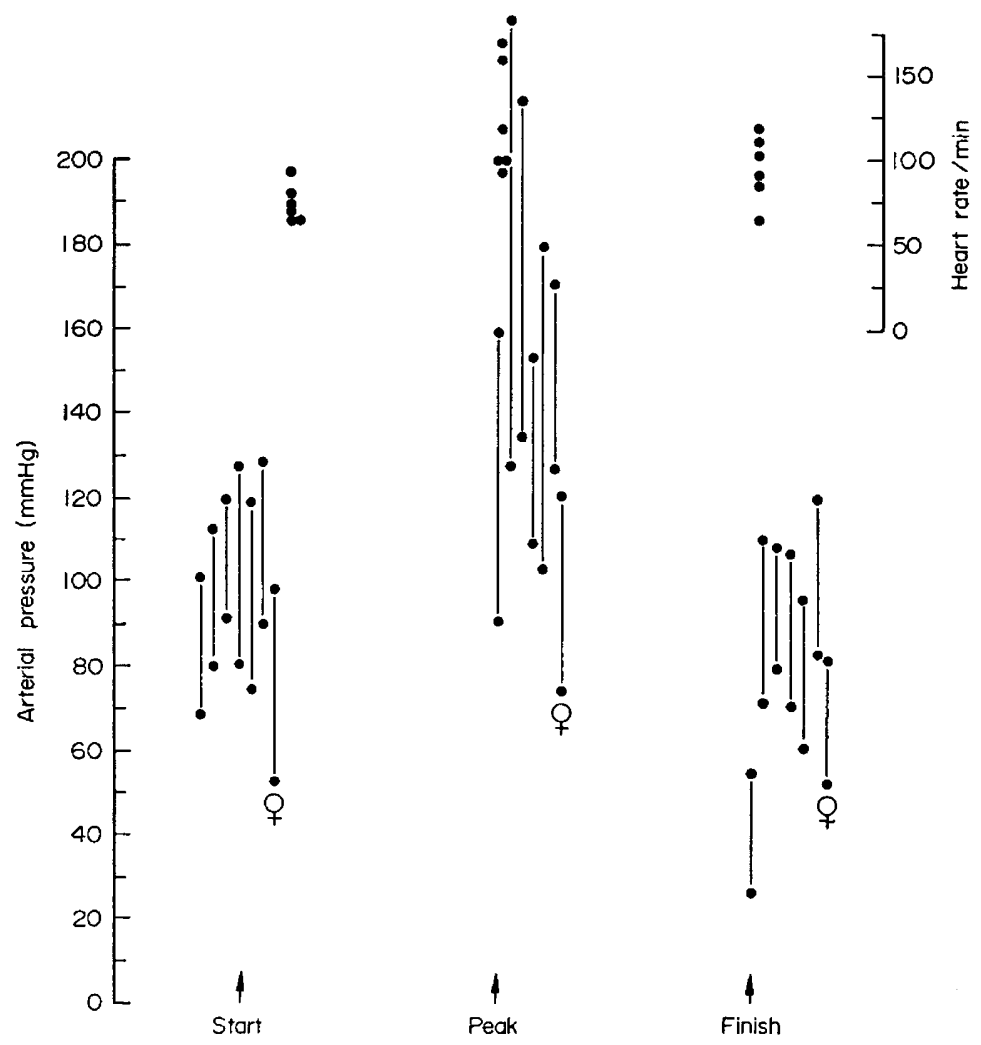

TExT-FIg. 1. The arterial blood pressure (-—) and heart rate (-) levels of seven human subjects during sexual intercourse; the peak levels in the males were achieved at orgasm. There is no heart rate record for Subject 1. 


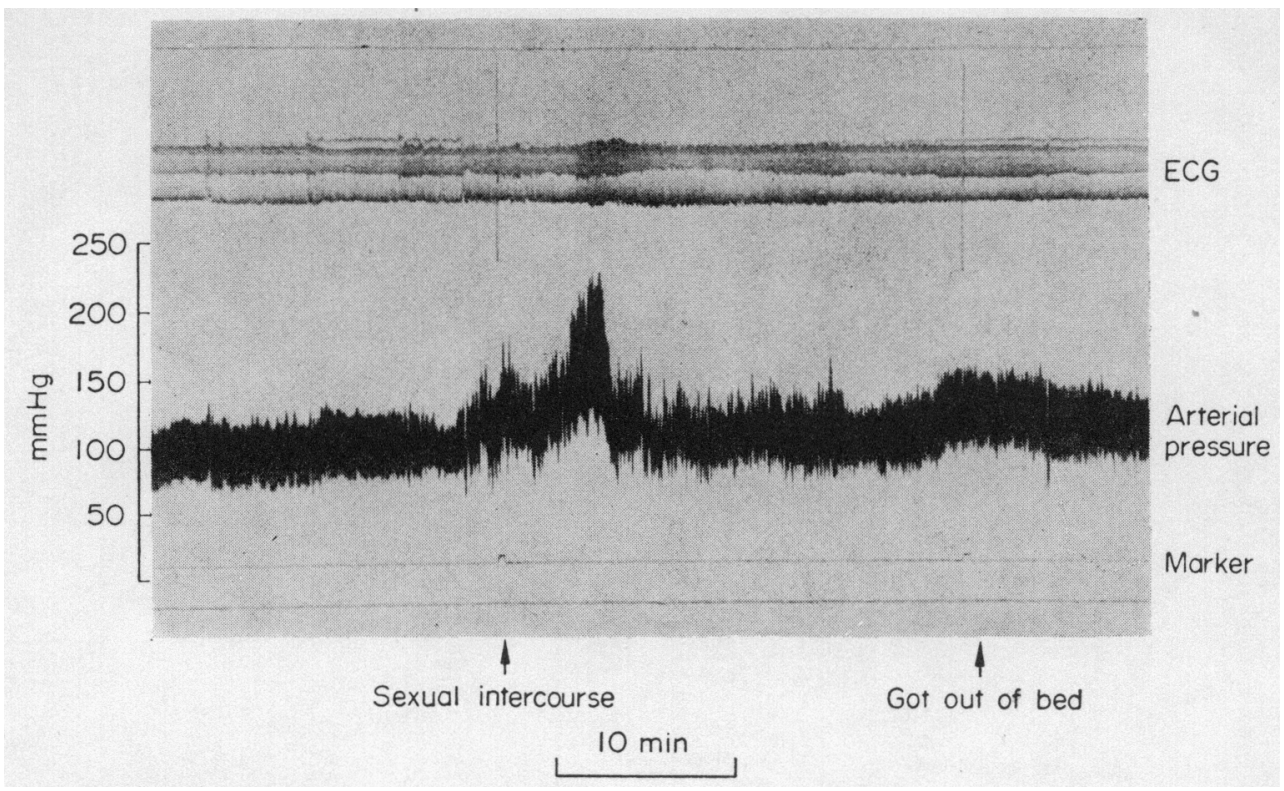

TExT-FIG. 2. A tracing from Subject 2 showing the behaviour of arterial pressure during intercourse.

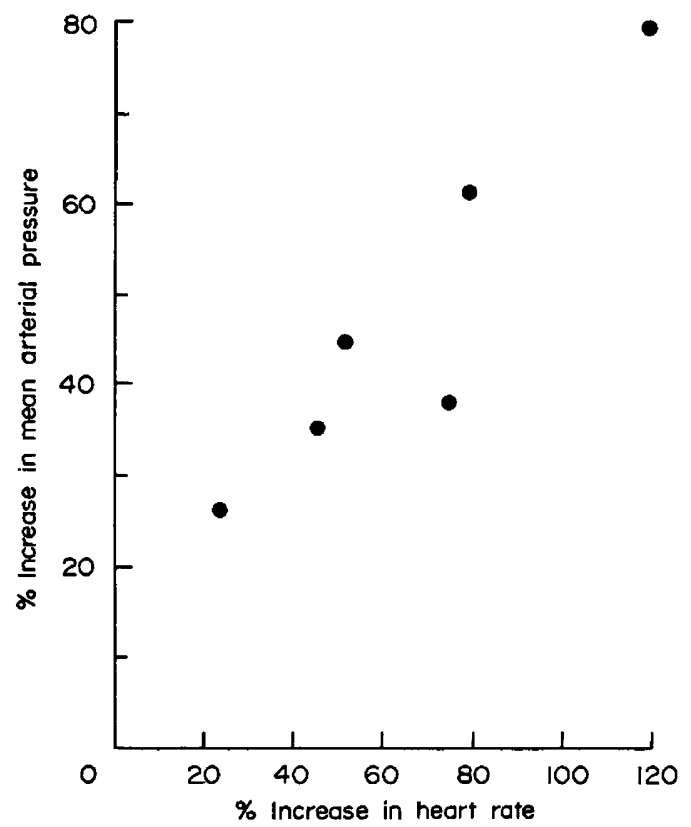

TEXT-FIG. 3. The relationship between the maximum $\%$ increase in mean arterial pressure and maximum $\%$ increase in heart rate during sexual intercourse in six subjects. 


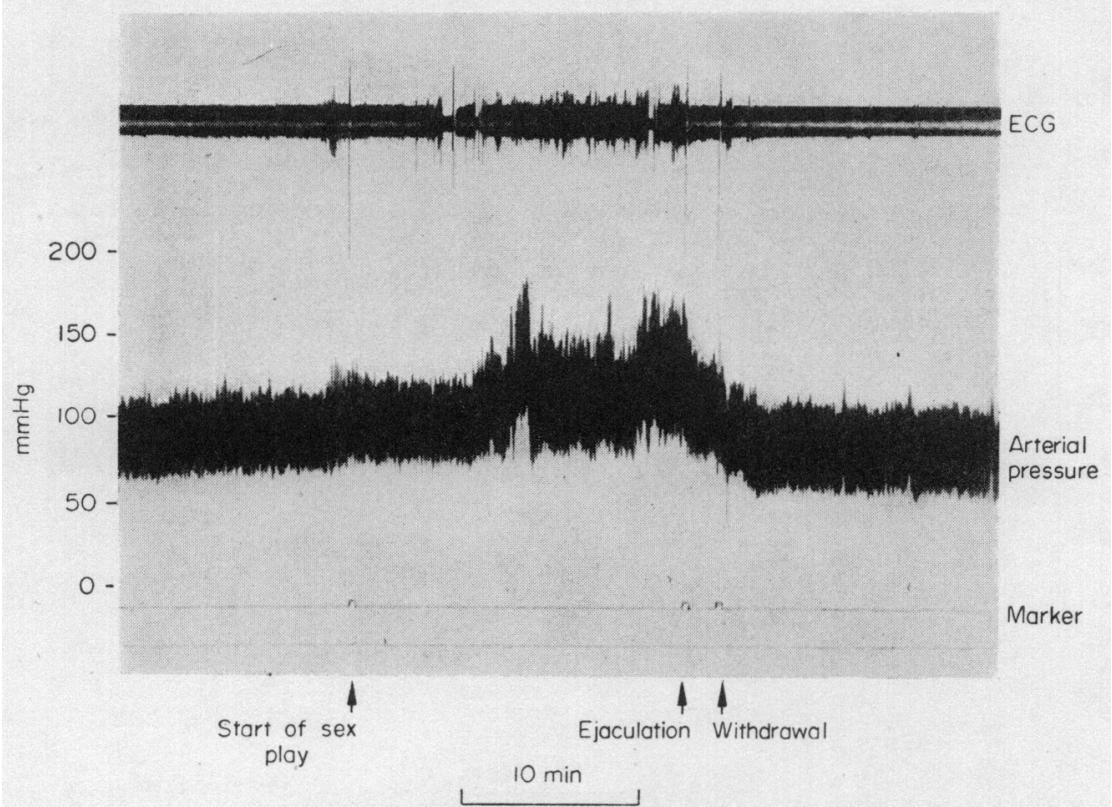

TEXT-FIG. 4. The behaviour of arterial pressure in Subject 5 who managed to indicate ejaculation and withdrawal. Note that the arterial pressure fell rapidly after orgasm.

subject, a small rise and fall in arterial pressure was recorded during the period of sexual activity (Text-fig. 6). In all male subjects during sexual activity, there were marked swings in arterial blood pressure and our records illustrate baroreceptor activity during this time (Text-fig. 7). Before orgasm, the pressure and heart rate seemed to be little influenced by these reflexes and increased pari passu.

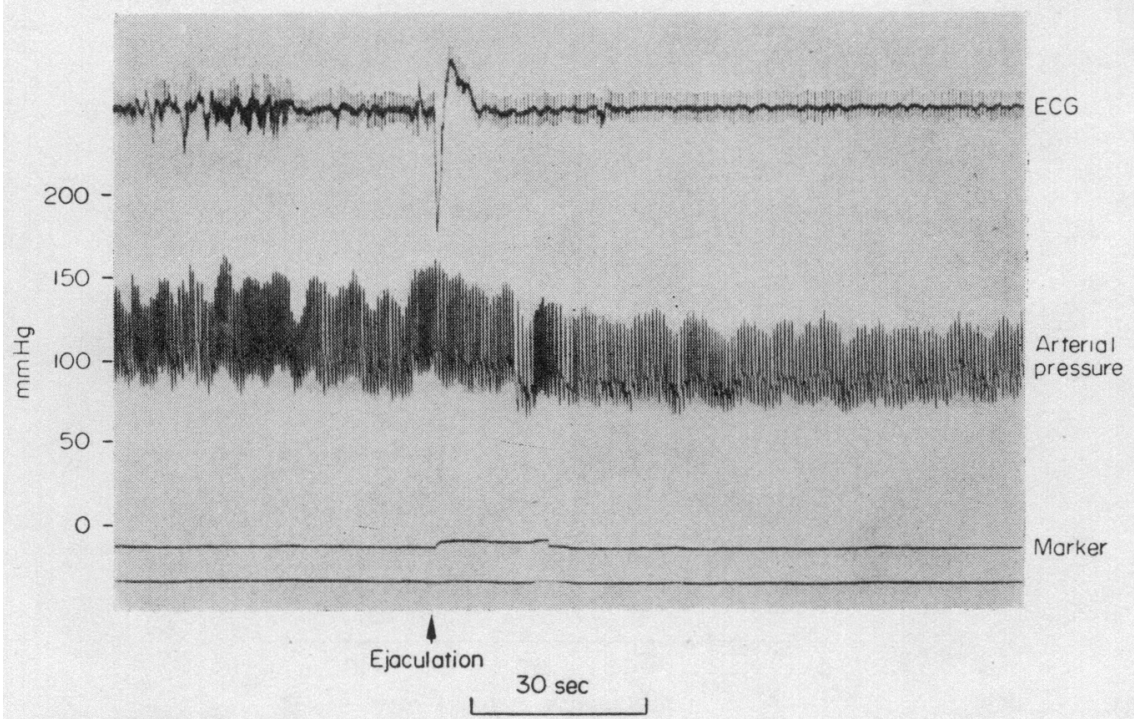

Texr-rig. 5. A beat-to-beat analysis of the data shown in Text-fig. 4, emphasizing the fall of arterial pressure following ejaculation. 


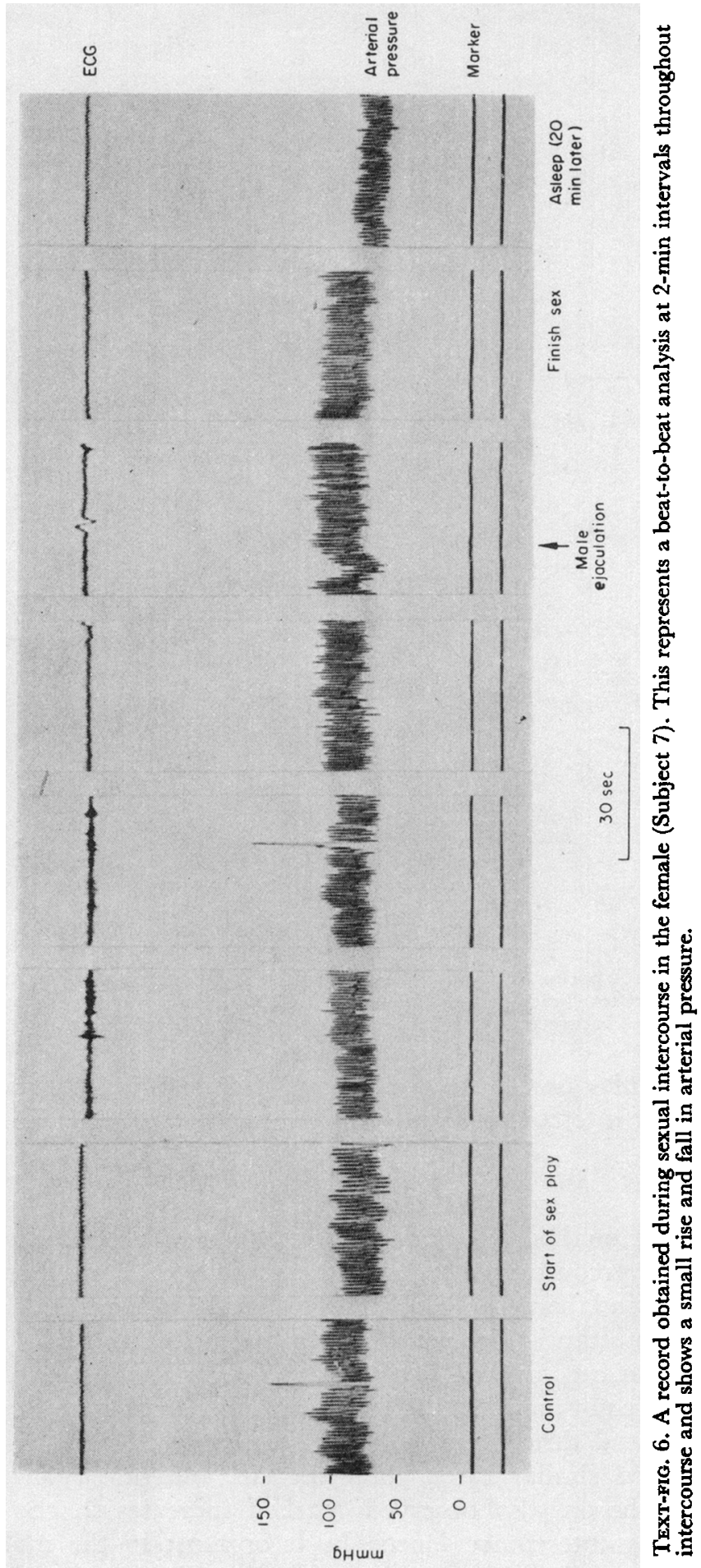




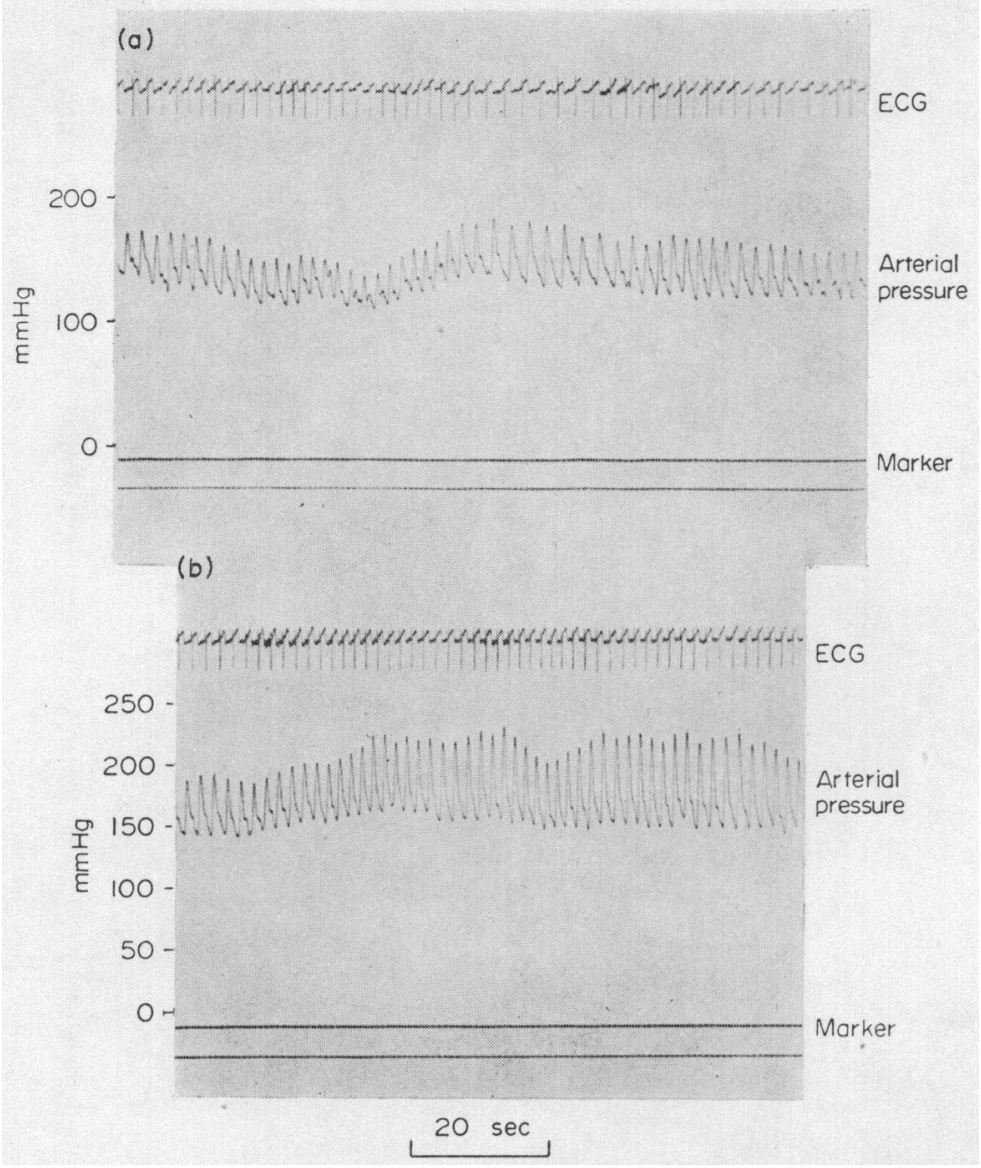

TEXT-FIG. 7. A portion of record from Subject 2 obtained during intercourse to demonstrate (a) reflex bradycardia with rising arterial pressure (baroreceptor activity), (b) the loss of baroreceptor activity immediately before orgasm.

No arrhythmias or ST segment changes were noted in any of the seven subjects during intercourse.

\section{DISCUSSION}

The recording methods used allowed the subjects great personal freedom. Since sexual intercourse took place in the home environment, most of the criticisms inherent in laboratory observations are not applicable. All seven subjects developed a substantial increase in heart rate and arterial pressure during sexual intercourse compared with the levels immediately beforehand. These observations are not unique. Bartlett (1956) recorded heart rates up to 170/min in three men and three women during intercourse, and Masters \& Johnson (1966) recorded similar rates; after orgasm, the rate returned to normal. Masters \& Johnson also observed marked increases in the arterial blood pressure during intercourse especially at orgasm; in the male, increases in systolic pressure of 40 to $100 \mathrm{mmHg}$ and in diastolic pressure of 20 to $50 \mathrm{mmHg}$ 
were recorded, and in the female, the increases were 30 to $80 \mathrm{mmHg}$ and 20 to $40 \mathrm{mmHg}$, respectively. These figures are in general agreement with our findings which suggest that the effect of being in a laboratory was not a contributory factor. Fox \& Fox (1969) made some elegant observations on systolic blood pressure (measured with a digital cuff) and respiratory pattern (measured with a Benedict Roth spirometer) during coitus. Their studies were carried out in one married couple with 10 years' mutual coital experience; orgasm was achieved by both partners. Systolic blood pressure rose by $100 \mathrm{~mm}$ to a peak of $200 \mathrm{mmHg}$ in the female, and by $65 \mathrm{~mm}$ to $175 \mathrm{mmHg}$ in the male, both the peak figures being obtained at orgasm. In a second series of studies (Fox, 1970), these rises in systolic blood pressure were reduced by the $\beta$-adrenergic-blocking drug, Propranolol. Our female subject did not show such large swings in pressure, although there was a definite increase compared with the pressure at the start of coitus. The failure to achieve orgasm probably accounted for the much smaller rise in pressure in the female.

We suggest that part of these circulatory changes are due directly to the effect of exercise. The response to exercise is complex, involving a number of variables including heart rate, stroke volume, sympathetic activity, excitement, apprehension, training and posture (Linden, 1965; Braunwald, Sonnenblick, Ross, Glick \& Epstein, 1967). Exercise is not commonly undertaken whilst supine but, during spontaneous uncontrolled exercise in this position under laboratory conditions, there is an increase in cardiac output which results almost entirely from an increase in heart rate; stroke volume showing a variable change (Chapman, Fisher \& Sproule, 1960; Braunwald et al., 1967). In the supine position, this increase in heart rate with mild exercise is mediated predominantly by a decreased parasympathetic activity; at higher levels of work, however, sympathetic activity also contributes to cardiac acceleration (Robinson, Epstein, Beiser \& Braunwald, 1966). Probably other mechanisms besides the autonomic nervous system are concerned in increasing the heart rate during severe exertion.

During muscular exercise, there is usually a significant increase in systolic and mean arterial blood pressures. With the onset of exercise, arterial pressure is maintained reflexly through the baroreceptors, an increase in arterial pressure being opposed by a bradycardia. However, this sympathetic inhibition by the baroreceptors is overwhelmed by a generalized stimulation of the sympathetic system by mechanisms not completely understood. Bristow \& co-authors (1971) have shown that during bicycling the reflex sensitivity of the baroreflex is progressively decreased so that at a level of exercise which produced a heart rate of 150 beats/min, the reflex was abolished. Text-figure 7 demonstrates baroreceptor activity during sexual intercourse. The upper panel shows reflex slowing of the heart during the early stages of sex-play. Immediately before ejaculation (lower panel), the pressure and rate rise pari passu, suggesting that the reflex has been over-ridden.

During sexual intercourse, there was a significant rise in diastolic arterial pressure, suggesting that the sympathetic drive was also affecting peripheral vessels. With the 'excitement' generated by intercourse, there is presumably a high background of autonomic activity with strong central stimuli. 
In the male, the peak for these marked circulatory changes is reached with ejaculation. After orgasm, arterial blood pressure and, to a lesser extent, heart rate fall to below control levels within $120 \mathrm{sec}$ (Text-fig. 5). Similar rapid falls in arterial pressure may be seen after other forms of exertion (Davson \& Eggleton, 1968). Scrutiny of the complete 24-hr record of each of the seven subjects to see if similar circulatory changes were produced by other activities revealed no such marked rises in diastolic pressure, though the subjects did not perform other forms of exercise in the supine position. Text-figure 8 shows part

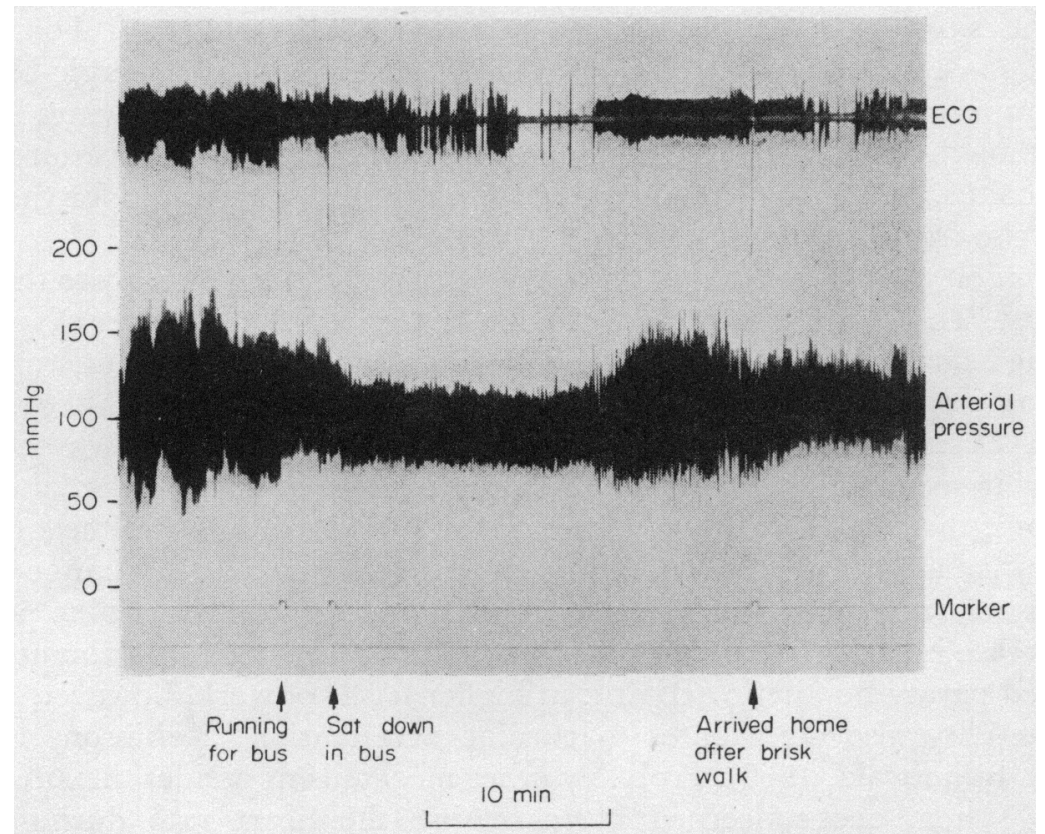

TEXT-FIG. 8. A tracing from Subject 5 showing the behaviour of the arterial blood pressure during muscular activity in the erect posture and when sitting at rest.

of a recording made during exercise in the erect position. The subject hurried for a bus, producing a significant rise in systolic arterial pressure, pulse pressure and heart rate (the latter is not obvious at this play-back speed); sitting in the bus, the systolic and pulse pressures quickly fell, but the diastolic pressure rose slightly.

Angina is not uncommon during intercourse in patients with ischaemic heart disease and despite the absence of significant arrhythmias or ST segment changes in the present study, the levels of pressure and rate change recorded here in normal people make it easy to see why this is so. Hellerstein \& Friedman (1970) studied sexual activity in forty-eight post-coronary patients and found that $20 \%$ developed angina during coitus. Fourteen of their patients wore a portable ECG recorder during coitus in the privacy of their homes and, of these, four patients experienced angina and developed ischaemic ST segment changes, two developed ischaemic changes and ectopic beats and a further four developed ectopic beats alone without any subjective pain. 


\section{AGKNOWLEDGMENT}

We are grateful to the British Heart Foundation for financial support.

\section{REFERENCES}

Bartlett, R. G., JR (1956) Physiologic responses during coitus. F. appl. Physiol. 9, 469.

Bevan, A., Honour, A. J. \& Stott, F. D. (1969) Direct arterial pressure recording in unrestricted man. Clin. Sci. 36, 329.

Braunwald, E., Sonnenblick, E. H., Ross, J., Jr, Glick, G. \& Epstein, S. E. (1967) An analysis of the cardiac response to exercise. Circulation Res. 20, Suppl. 1, 44.

Bristow, J. D., Brown, E. B., Gunningham, D. J. G., Howson, M. G., Strange Petersen, E., PickerING, T. G. \& SLEIGHT, P. (1971) Effect of bicycling on the baroreflex regulation of pulse interval. Circulation Res. 28, 582.

Chapman, G. B., Fisher, J. N. \& Sproule, B. J. (1960) Behaviour of stroke volume at rest and during exercise in human beings. 7 . clin. Invest. 39, 1208.

Davson, H. D. \& Eggleton, M. G. (1968) Principles of Human Physiology, 14th edn. Churchill, London.

Fox, G. A. (1970) Reduction in the rise of systolic blood pressure during human coitus by the $\beta$-adrenergic blocking agent, propranolol. 7. Reprod. Fert. 22, 587.

Fox, C. A. \& Fox, B. (1969) Blood pressure and respiratory patterns during human coitus. $\mathcal{F}$. Reprod. Fert. 19, 405.

Hellerstein, H. K. \& Friedman, E. H. (1970) Sexual activity and the post-coronary patient. Archs intern. Med. 125, 987.

Linden, R. J. (1965) The regulation of the output of the mammalian heart. In The Scientific Basis of Medicine, Annual Reviews, p. 164. Athlone Press, London.

Littler, W. A., Honour, A. J. \& Sleight, P. (1973) Direct arterial pressure and electrocardiogram during motor car driving. Br. med. J. ii, 273.

Litrler, W. A., Honour, A. J., Steight, P. \& Stott, F. D. (1972) Continuous recording of direct arterial pressure and electrocardiogram in unrestricted man. Br. med. $\mathcal{F}$. iii, 76.

Littler, W. A., Honour, A. J., Sleight, P. \& Stott, F. D. (1973) Direct arterial pressure and the electrocardiogram in unrestricted patients with angina pectoris. Circulation, 48, 125.

Masters, W. H. \& Johnson, V. E. (1966) Human Sexual Response. Little, Brown \& Co., Boston.

Robinson, B. F., Epstein, S. E., Beiser, G. \& Braunwald, E. (1966) Control of heart rate by autonomic nervous system. Studies in man on the interrelation between baroreceptor mechanisms and exercise. Circulation Res. 19, 400. 